\title{
What are adolescent girls' and young women's pregnancy experiences, fertility desires, and HIV-related risk behaviors? Findings from DREAMS implementation science research in Zambia
}

Population Council

\section{Recommended Citation}

Population Council. 2020. "What are adolescent girls' and young women's pregnancy experiences, fertility desires, and HIV-related risk behaviors? Findings from DREAMS implementation science research in Zambia," DREAMS Results Brief. Washington, DC: Population Council. 


\section{WHAT ARE ADOLESCENT GIRLS' AND YOUNG WOMEN'S PREGNANCY EXPERIENCES, FERTILITY DESIRES, AND HIV-RELATED RISK BEHAVIORS?}

FINDINGS FROM DREAMS IMPLEMENTATION SCIENCE RESEARCH IN ZAMBIA

In Zambia, adolescent girls and young women (AGYW) are disproportionately affected by HIV/ AIDS, with 3 to 4 times as many AGYW aged 15-24 years living with HIV compared to boys and young men of the same ages. ${ }^{1} \mathrm{AGYW}$ also have a high pregnancy burden: close to one-third of Zambian girls have begun childbearing by age 19 , and few use modern contraceptives to prevent pregnancy (15-19: 10\%, 20-24: 33\%). ${ }^{2}$

The Population Council conducted implementation science research in Zambia and other countries across sub-Saharan Africa to build needed evidence to inform community-based, girl-centered HIV prevention programming. Critical to this process is understanding AGYW's fertility desires and contraceptive use behaviors in the context of high HIV transmission.

This brief summarizes key findings from a crosssectional survey with sexually active AG (15-19 years, $n=97)$ and $\mathrm{YW}(20-24$ years, $n=342)$ enrolled in DREAMS programming and residing in urban districts of Lusaka and Ndola. The survey was conducted between April and May 2018. We present descriptive analyses of pregnancy experience, fertility desire, contraceptive use, and HIV-related risk behaviors among sexually active AGYW (ever had sex).

\section{RESULTS}

\section{Who are the survey respondents (Table 1)?}

- Most sexually active AGYW were 20-24 years (median age: 21 years), and fewer than half were currently enrolled in school.

\section{KEY FINDINGS}

Many AGYW have already begun

childbearing, with a majority of pregnancies and childbirths occurring outside formal partnerships or marriage.

A majority of AGYW in current or recent partnerships expressed the desire to have children with their most recent partner.

Among currently and recently partnered AGYW, fewer than half report any modern contraceptive use.

AGYW who did not want children with their most recent partner were less likely to report using modern contraception than AGYW who wanted children.

AGYW tended to express fertility desires with less risky sexual partners, including those who reported being monogamous (having only one partner) or perceived themselves at lower risk of HIV exposure.

HIV testing is high among AGYW and may represent an avenue to strengthen linkages to contraceptive and reproductive health services.

Location: Kalingalinga in Lusaka and Lubuto in the Ndola district (within Copperbelt province)

Study Duration: 2016-2018

Funder: Bill \& Melinda Gates Foundation

For more information, contact Sanyukta Mathur (smathur@popcouncil.org). 


\begin{tabular}{|c|c|c|c|}
\hline & $\begin{array}{l}\text { ADOLESCENT } \\
\text { GIRLS } \\
\begin{array}{c}15-19 \\
\mathrm{~N}=97 \\
\%\end{array}\end{array}$ & $\begin{array}{l}\text { YOUNG } \\
\text { WOMEN } \\
\begin{array}{c}20-24 \\
\text { N=342 } \\
\%\end{array}\end{array}$ & $\begin{array}{l}\text { TOTAL } \\
\begin{array}{l}\mathrm{N}=439 \\
\%\end{array}\end{array}$ \\
\hline Mean age (standard deviation) & $18+0.8$ years & $22+1.5$ years & $21+2.2$ years \\
\hline $\begin{array}{l}\text { Education } \\
\quad \text { Currently in school }\end{array}$ & 48 & 42 & 43 \\
\hline $\begin{array}{l}\text { Civil status } \\
\text { Never been married* }\end{array}$ & 96 & 85 & 87 \\
\hline $\begin{array}{l}\text { Household characteristics } \\
\text { At least one parent has died } \\
\text { Gone without eating at least a whole day and night, past month }\end{array}$ & $\begin{array}{l}41 \\
24\end{array}$ & $\begin{array}{l}47 \\
16\end{array}$ & $\begin{array}{l}46 \\
18\end{array}$ \\
\hline $\begin{array}{l}\text { Relationship status } \\
\quad \text { Currently or recently (past } 12 \text { months) partnered }\end{array}$ & 87 & 83 & 84 \\
\hline $\begin{array}{l}\text { Sexual risk behaviors } \\
\text { Mean age at first sex } \\
\text { Tested for HIV, past } 12 \text { months } \\
\text { High self-perception of HIV risk } \\
\text { STI symptoms, past } 6 \text { months }\end{array}$ & $\begin{array}{l}16+1.9 \\
85 \\
9 \\
21\end{array}$ & $\begin{array}{l}19+2.5 \\
82 \\
16 \\
17\end{array}$ & $\begin{array}{c}18+2.6 \\
83 \\
14 \\
18\end{array}$ \\
\hline $\begin{array}{l}\text { Pregnancy and contraceptive experiences } \\
\text { Ever been pregnant* } \\
\text { Has at least } 1 \text { child**} \\
\text { Wants a(nother) child in the future* } \\
\text { Using any modern contraceptive method to prevent pregnancy* }\end{array}$ & $\begin{array}{l}37 \\
31 \\
78 \\
27\end{array}$ & $\begin{array}{l}31 \\
31 \\
87 \\
40\end{array}$ & $\begin{array}{l}36 \\
31 \\
85 \\
37\end{array}$ \\
\hline
\end{tabular}

$* p<0.05 ; * * p<0.01 ; * * * p<0.001$

- Most (84 percent) reported having a current or recent sexual partner (in the past 12 months). The vast majority of the respondents (87 percent) had never been married.

- While most AGYW reported having tested for HIV in the last year (83 percent), only 14 percent perceived they were at high risk of HIV exposure. Nearly onefifth reported experiencing STI symptoms.

- Approximately one-third of respondents reported at least one previous pregnancy and having at least one child. Most (85 percent) expressed a desire to have a child or more children in the future.

- Only one-third of sexually experienced AGYW reported current use of any modern contraceptive method. Nearly four times the number of AGYW in current/recent partnerships reported modern contraceptive method use than non-partnered AGYW (42 percent vs. 11 percent, $p<0.001$ ).

- Among AGYW self-reporting contraceptive use, condoms (male or female) were the most popular method (53 percent), followed by hormonal injections (25 percent) and pills (14 percent).
Condoms were preferred by currently/recently partnered AGYW, while injectables and pills were more popular among non-partnered AGYW.

\section{What are the pregnancy experiences and fertility desires among AGYW with current or recent partners (Table 2)?}

- Among AGYW with current or recent partners, onefourth already had already begun childbearing.

- A majority (68 percent) desired a(nother) child, but most wanted to wait at least five years before having a child or more children. A significantly higher proportion of YW (ages 20-24) wanted children sooner than 5 years compared to AG (ages 15-19).

\section{What are the relationship characteristics, contraceptive use, and HIV risk behaviors among AGYW in a current or recent partner- ship (Table 3)?}

- More than three-fourths of AGYW who did not want children with their current/recent partner were not 

PARTNERS

\begin{tabular}{|c|c|c|c|}
\hline & $\begin{array}{c}\text { ADOLESCENT GIRLS } \\
\begin{array}{c}15-19 \\
\text { N=84 } \\
\%\end{array}\end{array}$ & $\begin{array}{c}\text { YOUNG WOMEN } \\
\begin{array}{c}20-24 \\
N=283 \\
\%\end{array}\end{array}$ & $\begin{array}{c}\text { TOTAL } \\
\begin{array}{c}\mathrm{N}=367 \\
\%\end{array}\end{array}$ \\
\hline Ever been pregnant & 29 & 39 & 37 \\
\hline $\begin{array}{l}\text { Parity* } \\
\text { Nulliparous (no children) } \\
\text { Multiparous (one or more) }\end{array}$ & $\begin{array}{l}80 \\
20\end{array}$ & $\begin{array}{l}66 \\
34\end{array}$ & $\begin{array}{l}69 \\
31\end{array}$ \\
\hline $\begin{array}{l}\text { Fertility desires } \\
\text { Wants a/another child with current/recent partner }\end{array}$ & 60 & 70 & 68 \\
\hline $\begin{array}{l}\text { When want a/next child (among those who desired } \\
\text { children } n=315 \text { )*** } \\
\text { Within the next year } \\
\text { In } 2-4 \text { years } \\
\text { In } 5 \text { or more years }\end{array}$ & $\begin{array}{c}3 \\
19 \\
78\end{array}$ & $\begin{array}{l}10 \\
40 \\
51\end{array}$ & $\begin{array}{c}8 \\
35 \\
57\end{array}$ \\
\hline Mean number of children desired (standard deviation) & $3.6+1.1$ & $3.6+1.2$ & $3.6+1.2$ \\
\hline
\end{tabular}

${ }^{*} \mathrm{p}<0.05 ; * * \mathrm{p}<0.01 ; * * * \mathrm{p}<0.001$

using any modern contraceptive method to prevent pregnancy.

- Consistent condom use was low (35\%) among AGYW, irrespective of fertility intentions. However, half of the AGYW who wanted another child and $61 \%$ of those who did not want a child reported using condoms at last sex.
- AGYW had a lower fertility desire if they perceived they were at high risk of HIV acquisition or if they thought their partner had high HIV risk.

- AGYW had a lower desire for children when they knew their partner had other sexual partners.

- AGYW who had shared their HIV status to their partner had stronger desire for children compared to AGYW who had not.

\section{TABLE 3 RELATIONSHIP CHARACTERISTICS, CONTRACEPTIVE USE, AND HIV RISK BEHAVIORS AMONG} AGYW IN A CURRENT/RECENT PARTNERSHIP

\begin{tabular}{|c|c|c|c|}
\hline & $\begin{array}{c}\text { DOESN'T WANT } \\
\text { A(NOTHER) CHILD } \\
\text { N=119 } \\
\%\end{array}$ & $\begin{array}{c}\text { WANTS } \\
\text { A(NOTHER) CHILD } \\
\text { N=248 } \\
\%\end{array}$ & $\begin{array}{c}\text { TOTAL } \\
\text { N=367 } \\
\%\end{array}$ \\
\hline \multicolumn{4}{|l|}{ Relationship duration } \\
\hline Less than one year & 23 & 18 & 20 \\
\hline $1-4$ years & 67 & 63 & 64 \\
\hline 5 or more years & 10 & 19 & 16 \\
\hline \multicolumn{4}{|l|}{ Contraceptive use } \\
\hline Using any modern contraceptive method*** & 21 & 52 & 42 \\
\hline \multicolumn{4}{|l|}{ Condom use } \\
\hline Consistent condom use, past 12 months & 34 & 36 & 35 \\
\hline Used condom at last sex with current/recent partner & 61 & 51 & 54 \\
\hline \multicolumn{4}{|l|}{ HIV risk perception } \\
\hline AGYW likely exposed to HIV* & 21 & 12 & 15 \\
\hline Partner likely exposed to HIV*** & 45 & 19 & 27 \\
\hline \multicolumn{4}{|l|}{ Partner risk characteristics } \\
\hline Has other sexual partners** & 10 & 2 & 5 \\
\hline Tested for HIV, past 12 months & 78 & 86 & 83 \\
\hline \multicolumn{4}{|l|}{ HIV serostatus disclosure } \\
\hline AGYW disclosed status to partner** & 84 & 93 & 90 \\
\hline Partner disclosed status to AGYW & 78 & 79 & 79 \\
\hline
\end{tabular}

$* p<0.05 ; * * p<0.01 ; * * * p<0.001$ 
CONCLUSION AND RECOMMENDATIONS

Sexually active AGYW in Zambia are having children early but have different fertility intentions depending on their HIV risk perceptions, partner characteristic, and communication with their partner about their own HIV status. The following recommendations emerged from our findings:

- Assess AGYW's pregnancy experiences and fertility desires within the context of an HIV prevention program to meet AGYW's SRH needs while supporting HIV risk mitigation.

- Since HIV testing rates are high among AGYW, strengthen linkages between HIV \& family planning services and social and behavior change programming for AGYW.

- For AGYW who don't want a/another child, provide counseling on long-acting contraceptives.

- For AGYW who want a/another child, provide counseling and services to ensure safe conception options.

- Provide supportive counseling to AGYW to consider own and partner's HIV risk when deciding on the appropriate contraceptive choice.

- Leverage high uptake of HIV testing services among AGYW to introduce family planning messaging and offer contraception.

- Provide differentiated family planning services that address AGYW's shifting fertility intentions and contraceptive needs/preferences over time and with different partners.

- Strengthen AGYW's self-efficacy and access to dual protection methods (i.e., condoms) to prevent pregnancy and avoid HIV acquisition.

\section{REFERENCES}

1. Ministry of Health Zambia. 2019. "Zambia Population-based HIV Impact Assessment (ZAMPHIA) 2016: final report." Lusaka, Ministry of Health. Retrieved from Zambia: http://phia. icap.columbia.edu

2. Central Statistical Office (CSO) [Zambia], Ministry of Health (MOH) [Zambia], and ICF International. 2014. Zambia Demographic and Health Survey 2013-14. Rockville, Maryland, USA: Central Statistical Office, Ministry of Health, and ICF International.
POPULATION COUNCIL

Ideas. Evidence. Impact.
The Population Council confronts critical health and development issues-from stopping the spread of HIV to improving reproductive health and ensuring that young people lead full and productive lives. Through biomedical, social science and public health research in about 50 countries, the Council works with our partners to deliver solutions that lead to more effective policies, programs, and technologies to improve lives worldwide. Established in 1952 and headquartered in New York, the Council is a nongovernmental, nonprofit organization with an international board of trustees. popcouncil.org

Suggested citation: Population Council. 2020. “What are adolescent girls' and young women's pregnancy experiences, fertility desires, and HIV-related risk behaviors?: findings from implementation science research in Zambia," DREAMS Results Brief. Washington, DC: Population Council. 